\title{
HUBUNGAN MOTIVASI PERAWAT DENGAN DOKUMENTASI PELAKSANAAN PENGKAJIAN DALAM PROSES KEPERAWATAN
}

\author{
Ade sulistyalubis/18110121 \\ adesulistyalubis@gmail.com
}

\begin{abstract}
ABTSTRAK
Latar belakang: Proses pengkajian merupakan tahap awal dari proses keperawatan yang dilakukan secara sistematis dengan mengumpulkan data individu secara komperhensif terkait aspek biologis, psikologis, sosial, maupun spiritual. Tujuan: Pembandingan jurnal ini adalah untuk mengetahui hubungan motivasi perawat dengan pelaksanaan pengkajian dalam proses keperawatan. Metode: Jurnal ini menggunakan metode tersearch dan analisis dari berbagai sumber seperti buku teks, buku referensi jurnal dan e-book, dan juga membandingkan beberapa jurnal yang berhubungan motivasi perawat dengan dokumentasi pelaksanaan pengkajian dalam proses keperawatan. Hasil: penulisan jurnal ini diketahui hubungan motivasi perawat dengan dokumentasi pelaksanaan pengkajian dalam proses keperawatan bahwa keduanya saling berhubungan dengan pelaksanaan pengkajian dalam proses keperawatan.Kesimpulan: Berdasarkan hasil pembandingan dari beberapa jurnal terbukti bahwa motivasi perawat mempunyai hubungan yang signifikan dengan pelaksanaan pendokumentasian asuhan keperawatan sama dengan pelaksanaan pengkajian dalam proses keperawatan
\end{abstract}

\section{Kata Kunci: Motivasi, Pengkajian, Proses Keperawatan}

Background: The assessment process is the initial stage of the nursing process that is carried out systematically by collecting individual data in a comprehensive manner related to biological, psychological, social, and spiritual aspects. Objective: Comparison of this journal is to determine the relationship of nurse motivation with the implementation of assessment in the nursing process. Method: This journal uses the search method and analysis from various sources such as textbooks, journal reference books and e-books, and also compares several journals related to nurse motivation with documentation of the implementation of assessment in the nursing process. Results: the writing of this journal is known to the relationship between nurses' motivation and the documentation of the implementation of the assessment in the nursing process that both are interrelated with the implementation of the assessment in the nursing process. Conclusion: Based on the results of a comparison of several journals it is evident that the motivation of nurses has a significant relationship with the implementation of documentation of nursing care together with the implementation of the assessment in the nursing process

Keywords: Motivation, Assessment, Nursing Process 


\section{PENDAHULUAN}

\section{LATAR BELAKANG}

Pengkajian merupakan kunci
untuk membuat keputusan klinis,
mengetahui keadaan pasien, serta
mengetahui masalah pasien (Potter \&
Perry, 2005). Pengkajian adalah pemikiran dasar dari proses keperawatan yang bertujuan untuk mengumpulkan informasi atau data tentang klien, agar dapat mengidentifikasi, mengenali masalahmasalah, kebutuhan kesehatan dan keperawatan klien, baik fisik, mental, sosial dan lingkungan.

$$
\text { Melakukan pengkajian }
$$

keperawatan merupakan salah satu bagian dari asuhan keperawatan. Pengkajian keoerawatan tidak hanya pada kesehatan fisik saja tetapi meliputi pemenuhan dasar kebutuhan manusia baik kebutuhan biologis, psikologis, sosial, dan spiritual yang utuh dan unik. Seperti dalam pemenuhan asuhan keperawatan spiritual masih kurangnya motivasi perawat dalam pemenuhan kebutuhan spiritual. Motivasi merupakan sekumpulan daya yang mendorong seseorang untuk berperilaku dan menetapkan perilaku berdasarkan bentuk, arah, intensitas dan durasinya (Streers, 2006).

Berdasarkan beberapa pendapat ahli (Claude S. George) yang dikutip dari penelitian Zuidah (2006) mengatakan bahwa motivasi seseorang berkaitan dengan kebutuhan meliputi tempat dan suasana lingkungan kerja sehingga penurunan motivasi perawat mengakibatkan hasil kerja yang tidak memuaskan dan hasil tindakan perawat menurun. Seperti belum optimalnya pelaksanaan asuhan keperawatan secara holistik termasuk keperawatan spiritual.

Dalam penelitiannya Pomatahu (2010) mengatakan motivasi perawat merupakan kunci utama keberhasilan penerapan asuhan keperawatan. Perawat bukan hanya sebagai tenaga kerja dalam kegiatan asuhan keperawatan tetapi harus diberikan peran dan tanggung jawab dalam semua proses pelayanan kesehatan. Vroom dalam Gibson dan Donelly (1991), motivasi adalah proses pengaturan pilihan diantara bentuk-bentuk aktivitas sukarela alternative. Menurut pandangannya, sebagian besar perilaku dianggap di bawah pengendalian orang dan karenanya dimotivasi. 
Proses keperawatan merupakan metode ilmiah yang dipakai dalam memberikan asuhan keperawatan yang profesional. Perawat, dimana saja ia bertugas, menghadapi klien dengan segala macam kasus, dan melayani klien pada semua tingkat usia juga harus menggunakan proses keperawatan. Perawat diharapkan memahami tentang konsep proses keperawatan dan mampu menerapkan serta menyusunannya dalam sebuah dokumen status kesehatan klien (Rohmah, N dan Walid, S. 2009).

\section{TUJUAN}

Tujuan pembandigan dari beberapa jurnal dan sumber lainnya agar dapat mengetahui bahwa hubungan antarara motivasi perawat dengan dokumentasi pelaksanaan pengkajian dalam proses keperawatan berhubangan erat yang dapat meningkatkan kualitas perawat dalam melakukan pengkajian dalam proses keperawatan.

\section{METODE}

Jurnal ini menggunakan metode tersearch dan analisis dari berbagai sumber seperti buku teks, buku referensi jurnal, e- book, dan juga membandingkan beberapa jurnal yang berhubungan dengan motivasi perawat dengan dokumentasi pelaksanaan pengkajian dalam proses keperawatan.

Dari analisi berbagai sumber digunakan Untuk mengetahui hubungan motivasi perawat dengan dokumentasi pelaksaan pengkajian dalam proses keperawatan. Penulisan jurnal ini dimulai pada tanggal 06 oktober 2019. Pengolahan jurnal dilakukan dengan metode membandingkan beberapa jurnal yang berhubungan dengan motivasi perawat dengan dokumantasi pelaksanaan pengkajian dalam proses keperawatan.

\section{HASIL}

Hasil pembandingan ini sesuai dengan penelitian Pakudek dkk (2013), Bara dan Suryati (2014), dan penelitian Agung (2009) yang membuktikan bahwa terdapat hubungan yang bermakna antara motivasi perawat dengan pelaksanaan dokumentasi keperawaratan yang artinya berhubungan dengan pengkajian dalam proses keperawatan. Pelaksanaan proses pengkajian keperawatan, meliputi (1) faktor pendorong perawat melakukan proses pengkajian; (2) metode pengumpulan data dalam proses 
pengkajian; (3) manfaat melakukan pengkajian; dan (4) faktor penghambat pelaksanaan proses pengkajian.

\section{Pelaksanaan pendokumentasian} asuhan keperawatan harus dilakukan dengan baik dan benar. Namun, hasil analisis menunjukkan bahwa masih banyak perawat yang belum melaksanakan pendokumentasian asuhan keperawatan dengan baik dan benar. Banyak faktor yang mempengaruhi pelaksanaan pendokumentasian asuhan keperawatan, salah satunya adalah motivasi dari perawat itu sendiri. Seperti yang diungkapkan oleh Setyarini (2004) yang menyebutkan bahwa motivasi merupakan salah satu dari factor faktor yang mempengaruhi pelaksanaan pendokumentasian asuhan keperawatan. Motivasi seseorang dapat berasal dari dua sumber, yaitu motivasi yang berasal dari dalam diri dan motivasi yang berasal dari luar diri seseorang.

$$
\text { Pelakanaan pendokumentasian }
$$
asuhan keperawatan mempunyai manfaat sebagai cara komunikasi, pertanggung jawaban dan pertangunggugatan, pendidikan, penelitian, meningkatkan efektivitas dan efisiensi, sumber data, dan menjamin kualitas pelayanan. Oleh karena itu, pelaksanaan pendokumentasian harus sesuai dengan standar dokumentasi asuhan keperawatan yang telah di tetapkan. Nursalam (2008) menyebutkan instrument studi dokumentasi penerapan standar asuhan keperawatan di RS menggunakan instrument A dari Depkes (1995) meliputi: pengkajian keperawatan, diagnose keperawatan, perencanaan tindakan, implementasi keperawatan, evaluasi keperawatan dan catatan asuhan keperawatan.

\section{PEMBAHASAN}

Dari Jurnal (Supratti, Ashriady. Pendokumentasian standar asuhan keperawatan di rumah sakit umum daerah mamuju, Indonesia.Vol 2. No 1, juli 2016.) Dapat diketahui Pengkajian adalah pemikiran dasar dari proses keperawatan yang bertujuan untuk mengumpulkan informasi atau data tentang klien agar dapat mengidentifikasi masalah-masalah yang dialami klien, mental, sosial dan lingkungan. Pengkajian yang sistematis dalam keperawatan dibagi dalam empat tahap kegiatan, yang meliputi pengumpulan data, analisis data, sistematika data dan penentuan masalah. Adapula yang menambahkannya dengan kegiatan dokumentasi data 
(meskipun setiap langkah dari proses keperawatan harus selalu didokumentasikan juga).

Hal-hal yang harus diperhatikan dalam pengkajian diantaranya adalah data yang dikumpulkan harus menyeluruh meliputi aspek bio-psikososial dan spiritual, menggunakan berbagai sumber yang ada relevansinya dengan masalah klien dan menggunakan cara-cara pengumpulan data yang sesuai dengan kebutuhan klien, dilakukan secara sistematis dan terus-menerus, dicatat dalam catatan keperawatan secara sistematis dan terus- menerus, dikelompokkan menurut kebutuhan biopsiko-sosial dan spiritual dan dianalisis dengan dukungan pengetahuan yang relevan (Yeni, 2008).

Faktor pendorong $\begin{array}{r}\text { perawat } \\ \text { melakukan proses }\end{array}$ pengkian
keperawatan adalah tahap proses
keperawatan yang harus dijalankan dan
prosedur tetap rumah sakit dalam
menerima pasien baru. Melakukan
pengkajian adalah proses pertama yang
dilakukan sebelum dapat melakukan
asuhan keperawatan pada pasien
(AlfaroLeFevre, 1994).
Motivasi adalah karakteristik psikologis manusia yang memberi kontribusi pada tingkat komitmen seseorang, termasuk faktor-faktor yang menyebabkan, menyalurkan dan mempertahankan tingkah laku manusia dalam arah tekad tertentu (Nursalam, 2008).

\section{KESIMPULAN}

Dari hasil pembandingan beberapa jurnal motivasi perawat mempunyai hubungan yang erat dengan pelaksanaan pendokumentasian asuhan keperawatan sama dengan pelaksanaan pengkajian dalam proses keperawatan. Pelaksanaan proses pengkajian keperawatan merupakan kegiatan komperhensif perawat yang membutuhkan motivasi, Melakukan pengkajian adalah proses pertama yang dilakukan sebelum dapat melakukan asuhan keperawatan pada pasien.

\section{SARAN}

Berdasarkan hasil pembandingan dari beberapa jurnal terbukti bahwa motivasi perawat mempunyai hubungan yang signifikan dengan pelaksanaan pendokumentasian asuhan keperawatan 
sama dengan pelaksanaan pengkajian dalam proses keperawatan. Oleh karena itu, motivasi perawat harus ditingkatkan melalui pelatihan-pelatihan dan pemberian reward agar perawat terdorong untuk melaksanakan pengkajian dalam proses keperawatan sesuai dengan standar asuhan keperawatan.

\section{REFERENSI}

Ali. (2010). Dasar-dasar Dokumentasi Keperawatan. Jakarta: EGC Arfiani, Rufianti. (2012). Hubungan Motivasi Kerja Perawat dengan pelaksanaan pendokumentasian proses Keperawatan Kesehatan Jiwa Di Ruang Rawat Inap Rumah Sakit Grhasia DIY. Skripsi. STIKES

A. Yani Yogyakarta Haryanto. (2007). Konsep dasar keperawatan dengan pemetaan konsep (concept mapping). Jakarta: Salemba Medika

Asmadi. (2008). Konsep Dasar Keperawatan. Jakarta: EGC

Bara, M dan Suryati, B. (2014). Hubungan

Motivasi Perawat dengan Pelaksanaan pendokumentasian Asuhan Keperawatan di Ruang Rawat Inap RSUD Pasar Rebo. Jurnal Health Quality. Volume 5 Nomor 1. Hlm: 1-16

Hidayat, A. A. A. (2002). Pengantar dokumentasi proses keperawatan. Jakarta:EGC.

Nursalam. (2011). Manajemen Keperawatan. Edisi 3. Salemba medika;287-94.

Rohmah, N.Integrasi proses keperawatan dalam pembelajaran klinik keperawatan one to one teaching and feed back. Vol. 1, No. 1, Desember 2010: The Indonesian Journal Of Health Science

Rohmah, N. dan Walid, S. (2009). Proses keperawatan, teori dan aplikasi dilengkapi dengan petunjuk praktis penyususnan proses keperawatan dan dokumentasi NANDANOCNIC. Arrus Media Jogjakarta. Rohmah, N. (2009). Dokumentasi Keperawatan. Buku Ajar Kuliah Dokumentasi Keperawatan. Prodi DIII Keperawatan Universitas Muhammadiyah Jember.

Supratti, Ashriady. Pendokumentasian Standar Asuhan Keperawatan di 
RSUD Mamuju, Indonesia. Vol 2. No 1, juli 2016: Jurnal Kesehatan MANARANG.

Simamora, R. H. (2019). Menjadi Perawat yang: CIH HUY. Surakarta: Kekata Publisher.

Simamora, Roymond H. 2010. Komunikasi dalam Keperawatan, Ed 1 hal 210. Jember: Univesity Press.

Simamora, Roymond H. Dokumentasi Proses Keperawatan, `Ed 1 hal 144. Jember: University Press.

Simamora, Roymond H. 2008. Peran Manajer dalam Pembinaan Etika Perawat Pelakasanaan dalam Peningkatan Kualitas Pelayanan Asuhan Keperawatan: Jurnal IKESMA, Ed 4, 2

Potter \& Perry. (2005). Buku Ajar Fundamental Keperawatan, Edisi 4. Jakarta : EGC.

Pakudek dkk. (2013). Hubungan Motivasi Perawat dengan Pelaksanaan Dokumentasi Asuhan Keperawatan di Instalasi Rawat Inap C RSUD prof. Dr. R.D. Kandau manado. E-Journal. Fakultas Kedokteran Universitas Sam Ratulangi Manado
Potter \& Perry. (2009). Fundamental of Nursing. 7 th Ed. St Louis Missouri: Elseiver

Perry, A. G., \& Potter, P. A. (2009). Potter and perry's fundamentals of nursing Australian version. (J. Crips \& C. Taylor, Eds.) ( $\left.3^{\text {rd }} \mathrm{ed}\right)$. Australian : mosby Elsevier Australia.

Potter, P. A., \& Perry, A. G., (2010). Fundamental of nursing. Buku 1, edisi 7. Jakarta : Salemba Medika.

Potter, P. A., \& Perry, A. G., (2013). Fundamentals of nursing. ( $\left.8^{\text {th }} \mathrm{ed}\right)$. Elsevier. 